\title{
Correlation of nasopharyngeal temperature with transcutaneous carotid artery temperature of adult patients under general anesthesia in rural tertiary care hospital
}

\author{
Akshaya N. Shetti, Bhavika Singla \\ Department of Anesthesiology, Rural Medical College, Pravara Institute of Medical Sciences (PIMS) University, Loni, Ahmednagar \\ District, Maharashtra State, India.
}

Correspondence: Dr. Bhavika Singla; E-mail: bhavikasingla201@gmail.com; Phone: +91 8291590945

\begin{abstract}
Background: Intraoperative temperature management is one of the important aspects in successful outcome of the surgical patient. Both anesthesia and surgery significantly have an impact on internal thermoregulation of the human body. We conducted this study to correlate nasopharyngeal temperature with transcutaneous carotid artery temperature of adult patients under general anesthesia (GA) in our rural institution.
\end{abstract}

Methodology: After approval of institutional ethical committee, a written informed consent was obtained from patients and this study was conducted on a sample of 40 patients. The sample size was calculated using previous study's correlation coefficient of .53. This correlation study was carried out at a rural teaching tertiary care hospital. After connecting monitoring system, GA was induced and maintained to all subjects as per institutional protocol. A nasopharyngeal probe and a skin probe were applied immediately after intubation. The carotid artery was palpated on right side and the cutaneous temperature probe was kept over the area where maximum impulse was felt. The sensor was covered with the gauze piece so that the ambient operating room temperature did not affect the reading. To equilibrate the temperature to surrounding tissue, after 5 min the first reading was noted and then every $15 \mathrm{~min}$ for one hour. The operating room temperature and humidity were kept constant.

Results: The transcutaneous skin temperature over the carotid artery showed statistically significant lower values than simultaneously measured nasopharyngeal temperature. This comparison was done with paired $t$-test $(p<0.05)$ and showed statistical significance. Pearson's correlation test showed both temperature measurements were strongly in correlation at 0 min, $15 \mathrm{~min}, 30 \mathrm{~min}, 45 \mathrm{~min}$ and $60 \mathrm{~min}$ time interval.

Conclusion: The transcutaneous carotid temperature was low in comparison to nasopharyngeal temperature for one hour postinduction. There is a strong correlation between the trans-nasopharyngeal and transcutaneous temperature measured over the carotid artery in adult patients undergoing elective surgery in the later phase.

Key words: temperature, carotid, transcutaneous, nasopharyngeal, general anesthesia

Citation: Shetti AN, Singla B. Correlation of nasopharyngeal temperature with transcutaneous carotid artery temperature of adult patients under general anesthesia in rural tertiary care hospital. Anaesth. pain intensive care 2020;24(3):302-307

Received: 6 August 2019, Reviewed: 13 December 2019, Revised: 14 December 2019, Accepted: 20 December 2019

\section{Introduction}

With the improvement in medical research various safety technology are invented. The patient safety is the main concern in any treatment. It is not uncommon to see that unmonitored patient body temperature may lead to perioperative complications. Both anesthesia and surgery significantly have an impact on internal thermoregulation of the human body. Therefore, temperature monitoring is now considered mandatory during surgical intervention under anaesthesia. ${ }^{1}$ Ideally, the core temperature monitoring is preferred 


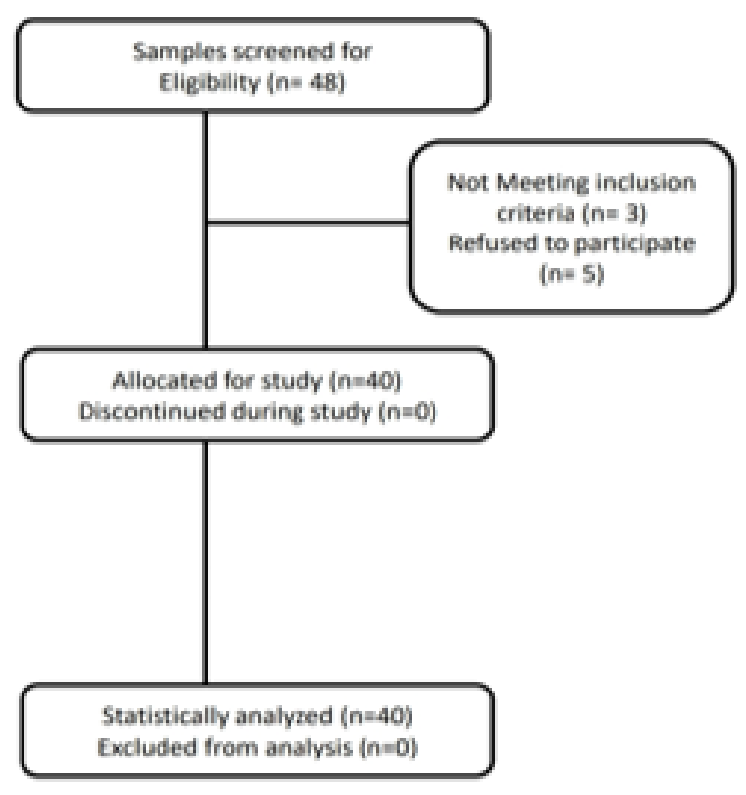

Figure-1:-Consort-diagramๆ

than peripheral temperature. The core thermal compartment is composed of highly perfused tissues whose temperature is uniform and higher compared to the rest of the body. This core temperature monitoring can be done at several sites viz., nasopharynx, esophagus, tympanic membrane, and the pulmonary artery. $^{2}$

Most of these techniques are invasive in nature. Both nasopharyngeal and esophageal temperatures are favored as primary indicators of intraoperative temperature status due to their proximity to the internal carotid artery and great vessels and heart, respectively. ${ }^{3}$ The peripheral sites of temperature monitoring like axillary, forehead, and abdominal skin are also utilized but they have poor reliability than the core temperature. ${ }^{4} \mathrm{~A}$ recent study in infants has shown that skin temperature over the carotid artery $\mathrm{T}_{\text {(skin carotid) }}$ is found to be highly correlated to nasopharyngeal temperature $\mathrm{T}_{\text {(naso) }}$ during perioperative management of infants. ${ }^{5}$

The temperature measurement is essential in any patient undergoing surgery, especially when surgery is of long duration. Our hypothesis was that the temperature readings between the nasopharyngeal and transcutaneous temperature will have similar findings.

\section{Methodology}

After approval of institutional ethical committee, a written informed consent was obtained from patients. This correlation study was conducted on 40 patients at our rural tertiary care teaching hospital.

Inclusion criteria were, patients of both sexes, ages between 20 to $45 \mathrm{y}$, ASA physical status I and II, undergoing surgery under general anesthesia (GA) for at least $1.5 \mathrm{~h}$ long procedure post-induction. Patients excluded were; unwilling to give consent, patients with known carotid artery pathology, surgeries where large amount of fluid shift was expected, suspected nasal deformity or nasal bone injuries, laparoscopic surgeries and patients having an episode of fever. Figure 1 depicts Consort diagram of the study population.

After connecting routine monitors for ECG, noninvasive $\mathrm{BP}, \mathrm{SpO}_{2}$, end tidal carbon dioxide $\left(\mathrm{EtCO}_{2}\right)$, pre-oxygenation was done with $100 \%$ oxygen for 3 min. All patients were pre-medicated with inj. fentanyl $2 \mu \mathrm{g} / \mathrm{kg}$, inj midazolam $0.05 \mathrm{mg} / \mathrm{kg}$ intravenously. They were then induced with inj. thiopentone $5 \mathrm{mg} / \mathrm{kg}$ and inj vecuronium $0.1 \mathrm{mg} / \mathrm{kg}$ administered intravenously. After $3 \mathrm{~min}$, the trachea was intubated with appropriate endotracheal tube size and connected to ventilator in a circle system. Anesthesia was maintained with oxygen and nitrous oxide $1: 1$, with isoflurane keeping end tidal concentration of 0.8 . The nasopharyngeal probe and the skin probe were applied immediately after intubation.

A nasopharyngeal temperature probe was inserted through one of the nostrils and fixed at depth which was equivalent to external distance between nares and the tragus. The left carotid artery was palpated and the cutaneous temperature probe was kept over the area where maximum impulse was felt. The sensor was covered with the gauze piece so that the external operating room temperature did not affect the recording (Figure 2).

To equilibrate the temperature to surrounding tissue, the first reading was noted after $5 \mathrm{~min}$; then every 15 min for one hour. The operating room temperature and humidity was also recorded. The primary outcome was to collect the temperature recording data as mentioned 


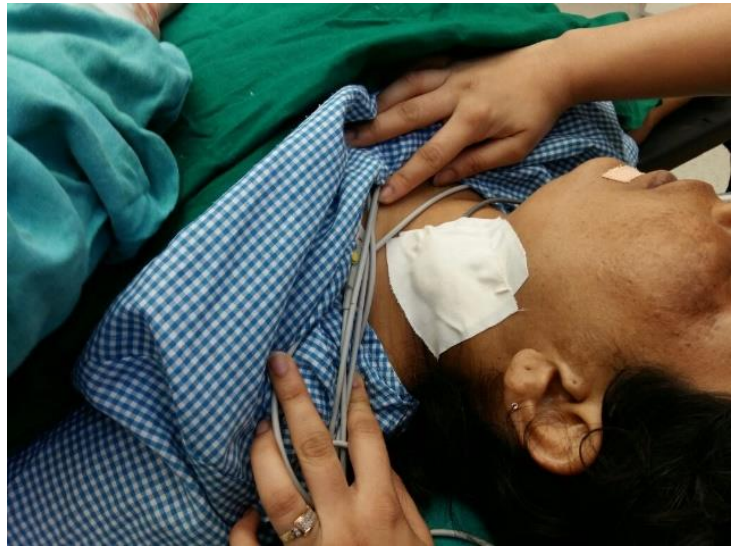

Figure 2: Position of temperature sensor over carotid artery

earlier and correlate nasal and transcutaneous carotid artery temperature.

\subsection{Statistical analysis}

The sample size was calculated by using android app "P-value: A statistical tool Vs, 1.3" based on a previous study. ${ }^{6}$ The Pearson correlation of previous study was 0.53 and based on it, the sample size obtained was 26 . Here the standard normal deviate alpha is $1.9(\mathrm{Z} \alpha)$, beta $(Z \beta)$ is 0.842 . The formula used was $\mathrm{N}=[(\mathrm{Z} \alpha$ $+\mathrm{Z} \beta$ ) $/ \mathrm{C}] 2+3=26$. Considering our case load in the hospital we collected data of 40 patients. The values between the sites measured at different time intervals was studied by using paired t-test using the 'GraphPad InStat' software.

\section{Results}

In the present study, 40 patients were included (Figure 2). Of these, $22(55 \%)$ were female and 18 (45\%) were males. The patients operated for general surgery, obstetrics and orthopedic procedures were 14 (35\%), 15 (37.5\%) and 11 (27.5\%) respectively. The operating room temperature was maintained at $22^{\circ} \mathrm{C}$ and humidity at 50 .

Table 1 shows the comparison of the temperature measurements between the two sites. Statistically (paired t-test) there was a significant difference in temperatures measured between the two sites. The trans-cutaneous carotid temperatures were lower in comparison with trans-nasopharyngeal temperatures at all the measurement time intervals i.e. 0, 15, 30, 45 and $60 \mathrm{~min}$.

Table 2 shows the correlation between the temperature measurements between the two monitoring sites. The results show extremely significant correlation between the two monitoring sites at all the measured intervals except at $30 \mathrm{~min}$, which shows there is a high correlation.

Figure 3 shows the Bland-Altman plot in which the distribution of mean temperature difference between trans-nasopharyngeal and transcutaneous carotid temperature at different time intervals i.e. $0,15,30,45$ and $60 \mathrm{~min}$ is depicted.

Table 1: Comparison of trans-nasopharyngeal and transcutaneous carotid temperature

\begin{tabular}{|c|c|c|c|c|c|c|c|}
\hline \multirow{2}{*}{ Time } & \multirow{2}{*}{ Site } & \multirow{2}{*}{ Mean \pm SD } & \multicolumn{2}{|c|}{ Cl } & \multirow{2}{*}{$\mathbf{t}$} & \multirow{2}{*}{ df } & \multirow{2}{*}{$\mathbf{p}$} \\
\hline & & & Lower & Upper & & & \\
\hline \multirow[t]{2}{*}{$0 \mathrm{~min}$} & Nasopharyngeal & $35.51 \pm 1.1$ & 35.13 & 35.89 & \multirow{2}{*}{11.23} & \multirow{2}{*}{39} & \multirow{2}{*}{$<0.0001$} \\
\hline & Transcutaneous Carotid & $33.84 \pm 1.5$ & 33.34 & 34.35 & & & \\
\hline \multirow[t]{2}{*}{$15 \min$} & Nasopharyngeal & $35.29 \pm 1.3$ & 34.87 & 35.71 & \multirow{2}{*}{10.17} & \multirow{2}{*}{39} & \multirow{2}{*}{$<0.0001$} \\
\hline & Transcutaneous Carotid & $34.18 \pm 1.4$ & 33.73 & 34.63 & & & \\
\hline \multirow[t]{2}{*}{$30 \min$} & Nasopharyngeal & $35.13 \pm 1.2$ & 34.74 & 35.51 & \multirow{2}{*}{4.19} & \multirow{2}{*}{39} & \multirow{2}{*}{0.0002} \\
\hline & Transcutaneous Carotid & $33.77 \pm 2.3$ & 33.03 & 34.52 & & & \\
\hline \multirow[t]{2}{*}{$45 \min$} & Nasopharyngeal & $34.64 \pm 0.9$ & 34.32 & 34.96 & \multirow{2}{*}{8.89} & \multirow{2}{*}{39} & \multirow{2}{*}{$<0.0001$} \\
\hline & Transcutaneous Carotid & $34.1 \pm 0.99$ & 33.78 & 34.42 & & & \\
\hline \multirow[t]{2}{*}{$60 \mathrm{~min}$} & Nasopharyngeal & $34.7 \pm 1.1$ & 34.39 & 35.12 & \multirow{2}{*}{8.21} & \multirow{2}{*}{39} & \multirow{2}{*}{$<0.0001$} \\
\hline & Transcutaneous Carotid & $34.1 \pm 1.2$ & 33.7 & 34.48 & & & \\
\hline
\end{tabular}

Test applied: paired t test,

$<0.0001=$ extremely significant, $0.0002=$ highly significant, $S D=$ standard deviation, $d f=$ degrees of freedom 
Table 2: Correlation of transnasopharyngeal and transcutaneous carotid temperature

\begin{tabular}{|c|c|c|c|c|c|c|c|}
\hline \multirow[b]{2}{*}{ Time } & \multirow[b]{2}{*}{ Site } & \multirow[b]{2}{*}{ Mean \pm SD } & \multicolumn{2}{|c|}{$\mathrm{Cl}$} & \multirow{2}{*}{$\begin{array}{l}\text { Pearson's } \\
\text { Correlation } \\
\text { coefficient (r) }\end{array}$} & \multirow[b]{2}{*}{ df } & \multirow[b]{2}{*}{$\mathbf{p}$} \\
\hline & & & Lower & Upper & & & \\
\hline \multirow[t]{2}{*}{$\mathrm{O} \min$} & Nasopharyngeal & $35.51 \pm 1.1$ & 35.13 & 35.89 & \multirow{2}{*}{0.80} & \multirow{2}{*}{39} & \multirow{2}{*}{$<0.0001$} \\
\hline & Transcutaneous Carotid & $33.84 \pm 1.5$ & 33.34 & 34.35 & & & \\
\hline \multirow[t]{2}{*}{$15 \mathrm{~min}$} & Nasopharyngeal & $35.29 \pm 1.3$ & 34.87 & 35.71 & \multirow{2}{*}{0.87} & \multirow{2}{*}{39} & \multirow{2}{*}{$<0.0001$} \\
\hline & Transcutaneous Carotid & $34.18 \pm 1.4$ & 33.73 & 34.63 & & & \\
\hline \multirow[t]{2}{*}{$30 \mathrm{~min}$} & Nasopharyngeal & $35.13 \pm 1.2$ & 34.74 & 35.51 & \multirow{2}{*}{0.48} & \multirow{2}{*}{39} & \multirow{2}{*}{0.0013} \\
\hline & Transcutaneous Carotid & $33.77 \pm 2.3$ & 33.03 & 34.52 & & & \\
\hline \multirow[t]{2}{*}{$45 \mathrm{~min}$} & Nasopharyngeal & $34.64 \pm 0.9$ & 34.32 & 34.96 & \multirow{2}{*}{0.92} & \multirow{2}{*}{39} & \multirow{2}{*}{$<0.0001$} \\
\hline & Transcutaneous Carotid & $34.1 \pm 0.99$ & 33.78 & 34.42 & & & \\
\hline \multirow[t]{2}{*}{$60 \mathrm{~min}$} & Nasopharyngeal & $34.7 \pm 1.1$ & 34.39 & 35.12 & \multirow{2}{*}{0.90} & \multirow{2}{*}{39} & \multirow{2}{*}{$<0.000$} \\
\hline & Transcutaneous Carotid & $34.1 \pm 1.2$ & 33.7 & 34.48 & & & \\
\hline
\end{tabular}

Test applied : Pearson's correlation test,

$<0.0001=$ extremely significant, $0.0013=$ highly significant, $S D=$ standard deviation, $d f=$ degrees of freedom

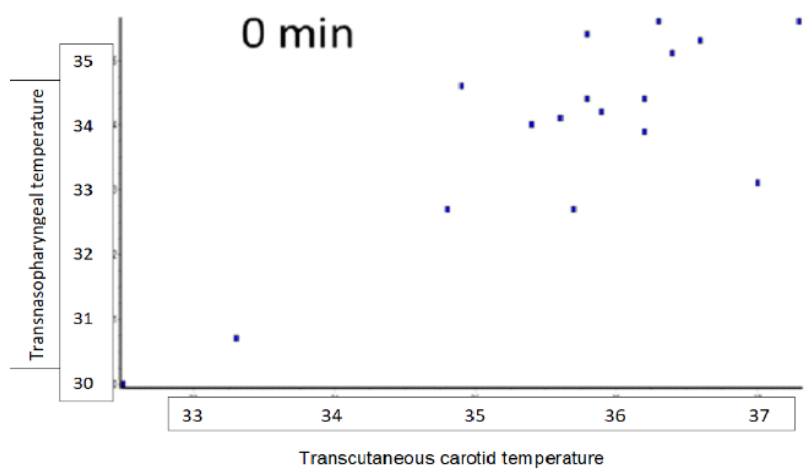

Figure 3: Bland-Altman plot at zero min

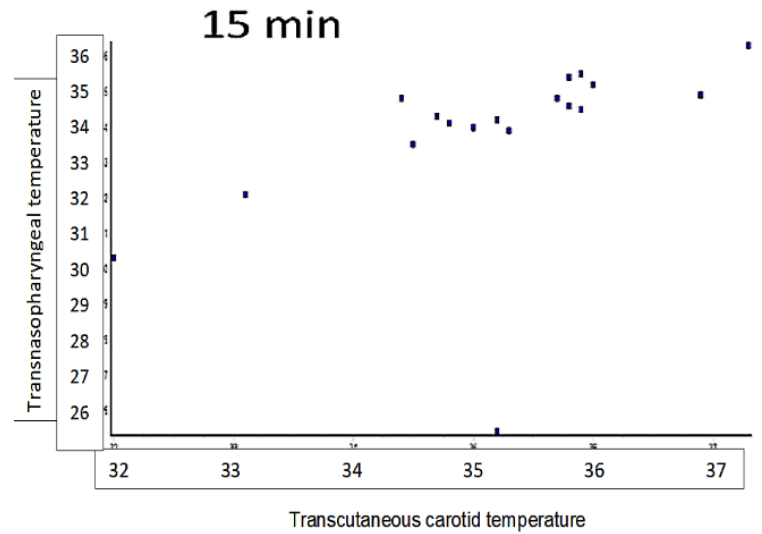

Figure 4: Bland-Altman plot at $15 \mathrm{~min}$

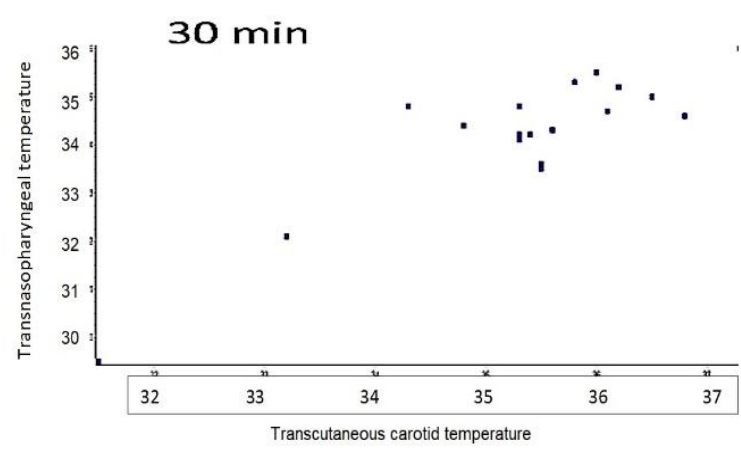

Figure 5: Bland-Altman plot at $\mathbf{3 0} \mathrm{min}$

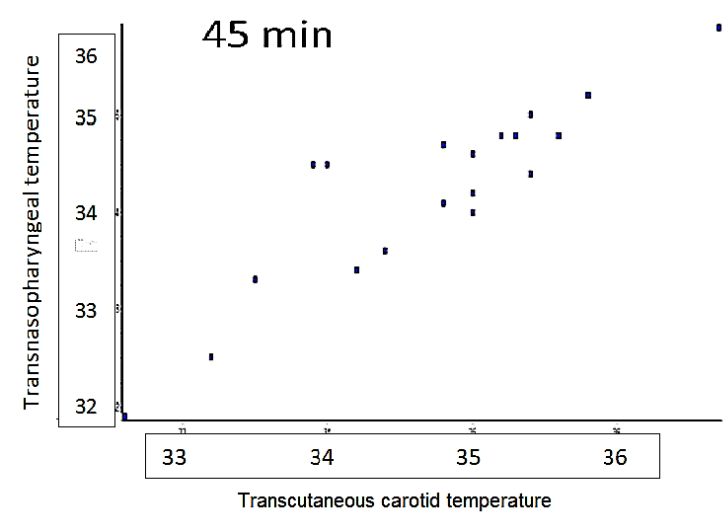

Figure 6: Bland-Altman plot at $\mathbf{4 5} \mathrm{min}$ 


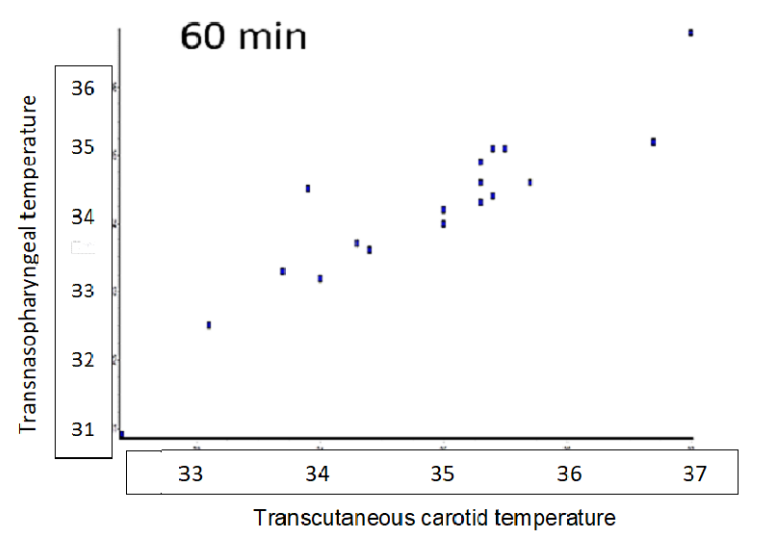

Figure 7: Bland-Altman plot at $60 \mathrm{~min}$

\section{Discussion}

The present study shows that skin temperature over the carotid artery can be used as a non-invasive method for estimating core body temperature like nasopharyngeal temperature in adult patients who are undergoing elective general surgery. Whenever a technique of monitoring is chosen, it is desirable to prefer a noninvasive, accurate, safe, continuous and easy procedure. In our study none of the patients in carotid group had any skin lesion. We chose carotid artery for this study as it is a large artery, easily approachable and near to the heart.

The data were collected and correlation between the nasopharyngeal and transcutaneous carotid body temperature was done using Bland-Altman analysis. In the present study, it was shown that the method of measuring skin temperature over carotid artery had an acceptable accuracy in comparison with the nasopharyngeal temperature. It is also important to note that the cutaneous temperature over carotid artery is lower than nasopharyngeal temperature till one hour post induction. Hence this technique should not be considered for the surgeries of one hour duration. Similar studies have been conducted in infants and children where the skin temperature over carotid is comparable with the rectal temperature. ${ }^{7}$ In another study, the author concluded that skin temperature over carotid is comparable with nasopharyngeal temperature with correction factor of $+0.52^{\circ} \mathrm{C}$. $^{6}$ Our results are in agreement with the study conducted by Venkatesh et al. ${ }^{8}$ Since the transcutaneous carotid temperature monitoring is a non-invasive technique with acceptable accuracy in core temperature monitoring this can routinely be used. The problems related to invasive techniques e.g., trauma or cross infection can easily be avoided.

\section{Limitations}

Patients undergoing laparoscopic surgery and in which large hemodynamic shifts were expected, were not included. Hence, further studies involving such cases may be conducted. Though we included only the young patients in our study, preoperative assessment of the status of the carotid artery is warranted, which may act as a confounding factor. Further studies may also be required in prolonged surgeries to know how the temperature monitoring correlates.

\section{Conclusion}

The transcutaneous carotid temperature was low in comparison to nasopharyngeal temperature for one hour post-induction. There is a strong correlation between the trans-nasopharyngeal and transcutaneous temperature measured over the carotid artery in adult patients undergoing elective surgery in the later phase.

\section{Conflict of interest}

Authors declare no conflict of interest.

\section{Authors' Contribution}

AS, BS: Concept, design, literature search, conduction of study, data acquisition, statistical analysis, manuscript preparation and editing.

BS: Guarantor and overall supervisor

\section{References}

1. Mance MJ. Keeping infants warm: challenges of hypothermia. Adv Neonatal Care. 2008;8(1):6-12. [PubMed] DOI: 10.1097/01.ANC.0000311011.33461.a5

2. Hannenberg $A A$, Sessler DI. Improving perioperative temperature management. Anesth Analg. 2008;107(5):1454-1457. [PubMed] DOI: 10.1213/ane.0b013e318181f6f2

3. WHO. Thermal control of a newborn: a practical guide. Geneva: World Health Organisation (WHO); 1996 
4. Bissonnette B, Sessler DI. The thermoregulatory threshold in infants and children anesthetized with isoflurane and caudal bupivacaine. Anesthesiology. 1990;73(6):1114-1118. [PubMed]

DOI: 10.1097/00000542-199012000-00008

5. Bissonnette B, Sessler DI. Thermoregulatory thresholds for vasoconstriction in pediatric patients anesthetized with halothane or halothane and caudal bupivacaine. Anesthesiology. 1992;76(3):387-392. [PubMed] DOI: 10.1097/00000542-199203000-00011

6. Jay $O$, Molgat-Seon $Y$, Chou S, Murto K. Skin temperature over the carotid artery provides an accurate noninvasive estimation of core temperature in infants and young children during general anesthesia. Paediatr
Anaesth. 2013;23(12):1109-1116. [PubMed] DOI: 10.1111/pan.12262

7. Imani F, Karimi Rouzbahani HR, Goudarzi M, Tarrahi MJ, Ebrahim Soltani A. Skin temperature over the carotid artery, an accurate non-invasive estimation of near core temperature. Anesth Pain Med. 2016;6(1):e31046. [PubMed] DOI: 10.5812/aapm.31046

8. Selvaraj V, Gnanaprakasam PV. Evaluation of skin temperature over carotid artery for temperature monitoring in comparison to nasopharyngeal temperature in adults under general anesthesia. Anesth Essays and Res. 2016;10(2):291-296. [PubMed] DOI: $\underline{10.4103 / 0259-1162.172722}$ 